\title{
KECERDASAN BUDAYA DAN PENYESUAIAN DIRI DALAM KONTEKS SOSIAL-BUDAYA PADA MAHASISWA INDONESIA YANG KULIAH DI LUAR NEGERI
}

\author{
Anshari Al Ghaniyy ${ }^{1}$ \& Sari Zakiah Akmal ${ }^{2}$ \\ Fakultas Psikologi, Universitas YARSI, Jl. Letnan Suprapto, Cempaka Putih, Jakarta 10510, Indonesia
}

Korespondensi:

${ }^{1}$ e-mail: ghaniyyal.anshari@gmail.com; ${ }^{2}$ e-mail:sari.zakiah@gmail.com

\begin{abstract}
This study aims to investigate the relationship between the sociocultural adjustment and cultural intelligence in Indonesian students who study abroad. Sociocultural adjustment is the ability and competence to adapt in a new environment by facing everyday life difficulties in different cultural contexts. Cultural intelligence is an individual's ability to learn, manage, and interact in order to work effectively with culturally different societies. Cultural intelligence has two dimensions: internalised cultural knowledge intelligence (ICK) and effective cultural flexibility (ECF). Participants in this study were 105 Indonesian students who studied abroad at the time they participate. The data was processed with partial correlation by controlling for sex and the use of English. The results showed that ICK has a significant relation to sociocultural adjustment, while ECF is not significantly related to sociocultural adjustment. The findings highlight the importance of students to deepen the cultural and all aspects of the destination country in order to adapt well.
\end{abstract}

Article history:

Received 29 March 2018

Received in revised form 3 May 2018

Accepted 25 June 2018

Available online 19 September 2018

Keywords:

cultural intelligence;

overseas student;

sociocultural adjustment

\begin{abstract}
Abstrak - Penelitian ini bertujuan untuk mengetahui hubungan kemampuan penyesuaian diri dalam konteks budaya yang berbeda dengan kecerdasan budaya pada mahasiswa Indonesia yang kuliah di luar negeri. Kemampuan penyesuaian diri dalam konteks budaya adalah kemampuan dan kompetensi untuk dapat menyesuaikan diri dalam lingkungan yang baru dengan melihat kesulitan yang dihadapi dalam keseharian dalam konteks budaya yang berbeda. Kecerdasan budaya merupakan kemampuan individu untuk memelajari, mengelola, dan berinteraksi agar dapat bekerja secara efektif dengan masyarakat yang berbeda budaya. Kecerdasan budaya memiliki dua dimensi yaitu internalized cultural knowledge intelligence (ICK) yang membahas kemampuan kognitif dan effective cultural flexibility (ECF). Partisipan dalam penelitian ini ialah 105 mahasiswa Indonesia yang berkuliah di luar negeri saat berpartisipasi dalam penelitian ini. Data penelitian diolah dengan korelasi parsial dengan mengontrol jenis kelamin dan penggunaan bahasa Inggris. Hasil yang diperoleh dalam penelitian ini adalah ICK memiliki hubungan yang signifikan dengan penyesuaian diri dalam konteks budaya, sedangkan ECF tidak berhubungan signifikan dengan penyesuaian diri dalam konteks budaya. Hasil penelitian ini menekankan pentingnya mahasiswa untuk lebih mendalami kebudayaan dan segala aspek yang terdapat di negara tujuan agar dapat beradaptasi dengan baik.
\end{abstract}

Kata Kunci: kecerdasan budaya; mahasiswa luar negeri; penyesuaian sosiokultural 


\section{PENDAHULUAN}

Hidup di luar negeri dan berhadapan dengan budaya baru dipandang sebagai pengalaman menarik dan menyenangkan. Selain itu, dengan adanya tuntutan akan perolehan pendidikan yang lebih layak dan kebutuhan peningkatan status ekonomi dan sosial, maka banyak mahasiswa memutuskan untuk belajar di luar negeri. Beberapa keuntungan yang dapat diperoleh dengan melanjutkan pendidikan di luar negeri di antaranya: untuk meningkatkan kemampuan bekerja, dapat membangun kepercayaan diri dalam menguasai kemampuan baru dalam bekerja secara efektif, pengembangan diri, mampu memelajari diri sendiri, serta mampu meningkatkan kemampuan dalam mengatasi situasi yang ambigu (Bohrer, 2011; Dwyer \& Peters, 2004).

Terdapat beberapa alasan spesifik yang membuat masyarakat Indonesia banyak yang melanjutkan pendidikan di luar negeri, di antaranya adalah: pelajaran dan kualitas pendidikan yang lebih baik daripada di Indonesia, reputasi dari institusi pendidikan luar negeri yang dikenal baik, dan lingkungan belajar yang dirasa cukup nyaman (Mazzarol \& Soutar, 2002). Dari beberapa alasan tersebut, dapat diketahui bahwa banyak keuntungan yang dapat diperoleh mahasiswa yang kuliah di luar negeri. Mahasiswa Indonesia yang kuliah di luar negeri juga memiliki ekspektasi yang besar terhadap apa yang akan didapatkan dengan berkuliah di luar negeri.

Akan tetapi, banyak mahasiswa yang pindah dan melanjutkan hidup di luar negeri mengaku memiliki kesulitan dalam menyesuaikan diri dengan lingkungan yang baru dan merasakan perubahan emosi dari waktu ke waktu. Sebagai contoh, individu yang mengalami permasalahan dalam perubahan emosi dapat merasakan depresi dan bahagia dengan selisih waktu yang cukup singkat (Universitas Negeri Malang, 2017). Bukan hanya itu, ada pula yang sudah mampu beradaptasi di awal kedatangan, namun terdapat hal-hal yang tidak terduga yang membuat individu kesulitan untuk menyesuaikan diri dengan halangan-halangan yang terjadi karena persoalan budaya.

Penelitian ini menggali informasi permasalahan kehidupan mahasiswa Indonesia yang berkuliah di luar negeri. Berdasarkan informasi awal, diperoleh data yang dihimpun melalui penyebaran angket terhadap 76 mahasiswa Indonesia yang sedang berkuliah di luar negeri. Data tersebut menunjukkan bahwa sebagian besar mahasiswa Indonesia yang berkuliah di luar negeri mengalami kesulitan dalam beradaptasi. Faktor-faktor yang menyebabkan mahasiswa Indonesia yang kuliah di luar negeri kesulitan dalam beradaptasi adalah persoalan bahasa sebesar 34.72 
persen, sistem pendidikan di lingkungan yang baru sebesar 23.92 persen, kerinduan terhadap rumah (homesickness) sebesar 15.83 persen, perlakuan masyarakat lokal sebesar 13.13 persen, jumlah pendapatan sebesar 12.37 persen, kemudian diikuti dengan faktor makanan, cuaca dan iklim, serta hubungan pertemanan dengan masyarakat lokal. Faktor-faktor tersebut sesuai dengan penelitian Ward dan Kennedy (1999), Wang dan Mallinckrodt (2006), serta Smith dan Khawaja (2011).

Persoalan bahasa menjadi faktor utama yang menyebabkan sulitnya mahasiswa Indonesia yang kuliah di luar negeri dalam menyesuaikan diri di negara asing. Hal tersebut dikarenakan kemampuan berbahasa memengaruhi proses komunikasi, hubungan relasi, pengajar dan konselor, hingga hal-hal yang berkaitan dengan proses akademik dan non-akademik seperti transportasi, perizinan mengemudi, dan persoalan-persoalan terkait akomodasi (Bochner, Hutnik, \& Furnham, dalam Markova, 2006; Zhao, 2010). Selain faktor bahasa, faktor lain seperti sistem pendidikan di lingkungan yang baru, kerinduan terhadap rumah, serta perilaku masyarakat lokal dapat mengakibatkan stres dan menghambat proses penyesuaian diri, sehingga proses mahasiswa membutuhkan usaha yang lebih keras untuk dapat menyelesaikan studi di luar negeri (Wang \& Mallinckrodt, 2006; Smith \& Khawaja, 2011). Berdasarkan data-data di atas maka dapat diindikasikan bahwa mahasiswa Indonesia yang kuliah di luar negeri mengalami masalah dalam penyesuaian diri.

Pada dasarnya, proses penyesuaian memang akan dihadapi oleh individu yang memasuki lingkungan yang baru dan akan lebih sulit jika perbedaan tersebut cukup jauh (Ward \& Kennedy, 1999). Perbedaan tersebut dapat mencakup bahasa dan pemahaman kolektivis ataupun individualis. Contohnya, mahasiswa Malaysia di Singapura akan lebih mudah menyesuaikan diri dibandingkan dengan mahasiswa Malaysia di Selandia Baru, atau mahasiswa Cina yang juga tidak terlalu memiliki permasalahan penyesuaian diri dibandingkan dengan mahasiswa NonCina di Singapura (Ward \& Kennedy, 1999). Individu yang berpindah ke tempat yang lebih nyaman hanya merasakan sedikit kendala dalam penyesuaian diri (Ward \& Kennedy, 1999). Orang yang berasal dari Inggris, Selandia Baru, Amerika, dan Hong Kong tidak terlalu kesulitan dalam melakukan adaptasi di negara Singapura daripada di Nepal. Hal tersebut dikarenakan Singapura memiliki ragam budaya internasional yang sudah menetap sejak lama.

Penyesuaian diri terhadap budaya dan lingkungan yang baru disebut juga dengan penyesuaian diri dalam konteks budaya yang berbeda (sociocultural adjustment) (Searle \& Ward, 1990). Penyesuaian diri dalam konteks budaya yang berbeda didefinisikan sebagai suatu 
kompetensi perilaku untuk mengatasi permasalahan sehari-hari dan interaksi sosial dalam konteks lingkungan budaya yang baru (Searle \& Ward, 1990). Kemampuan dalam menyesuaikan diri terhadap budaya yang baru ini juga menggambarkan derajat kenyamanan seseorang secara psikologis dengan aspek-aspek yang terdapat di negara tuan rumah (Black, 1988). Definisi lain juga diutarakan oleh Guðmundsdóttir (2013) bahwa penyesuaian diri dalam konteks budaya yang berbeda merupakan kemampuan individu untuk mampu menyesuaikan diri dengan sebuah lingkungan baru yang dilihat dari kesulitan-kesulitan yang dialami dalam kehidupan sehari-hari.

Berdasarkan analisis faktor yang dilakukan oleh Ward dan Kennedy (1999), penyesuaian diri dalam konteks budaya yang berbeda terdiri dari dua dimensi. Dimensi pertama yaitu empati dan keterkaitan budaya (cultural empathy and relatedness) yang merupakan dimensi kognitif dan komunikasi. Dimensi ini meliputi pemahaman individu terhadap perspektif, pandangan, nilai-nilai lokal yang berlaku, serta bagaimana individu berinteraksi antar budaya yang berbeda, menjalin pertemanan, termasuk memahami diri sendiri (Ward \& Kennedy, 1999). Selanjutnya, dimensi kedua adalah dimensi upaya dan risiko impersonal (impersonal endeavors and peril). Dimensi ini mengacu pada aspek kemampuan individu dalam mengelola diri ketika berinteraksi dalam situasi yang dianggap tidak biasa dan berasal dari faktor eksternal (Ward \& Kennedy, 1999). Hal ini meliputi bagaimana kemampuan individu dalam menghadapi birokrasi dan aturan yang berlaku, pelayanan yang tidak memuaskan, dan menghadapi orang lain yang tidak menyenangkan (Ward \& Kennedy, 1999).

Kemampuan untuk menyesuaikan diri dalam konteks budaya yang berbeda merupakan hal yang penting untuk dimiliki oleh individu (Oatey \& Xiong, 2006). Beberapa dampak yang dapat ditimbulkan dari rendahnya penyesuaian diri dalam konteks budaya yang berbeda adalah kegagalan membangun hubungan sosial dengan orang lain, kondisi emosi individu yang dapat tersalurkan dengan cara yang negatif, serta memicu kemungkinan masalah tidur, kondisi fisik yang mudah lelah, merasa tidak dihargai, kesulitan dalam membuat keputusan, menyalahkan diri sendiri, merasa diintimidasi, dan berbagai macam permasalahan yang lain (Ward \& Kennedy, 1994; Universitas Negeri Malang, 2017; Bemak \& Chung, 1998).

Beberapa faktor yang dapat memengaruhi kemampuan menyesuaikan diri dalam budaya berbeda di antaranya adalah: kecerdasan emosi (emotional intelligence, EQ), lamanya berinteraksi dengan budaya asing, pengetahuan tentang budaya, jarak perbedaan antar budaya asal dan budaya di negara berkuliah, dan kelancaran dalam berbahasa (Koveshnikov, Wechtler, 
\& Dejoux, 2013; Ward \& Kennedy, 1999; Wilson, 2011). Adapun dalam konteks penyesuaian diri, kecerdasan emosi hanya menilai kemampuan seseorang dalam berinteraksi dan bekerja dengan orang lain (Mayer, Roberts, \& Barsade, 2008). Sementara itu, budaya memiliki cakupan yang lebih spesifik dengan adanya unsur-unsur budaya, seperti: zona waktu, bahasa, kebiasaan setempat, persamaan sejarah dan latar belakang budaya, serta aspek ekologi (Earley \& Ang, 2003). Selain itu, penyesuaian diri dalam konteks budaya yang berbeda juga dapat diprediksi melalui seberapa besar pengetahuan dan kompetensi individu tersebut terhadap budaya di negara yang ditempati (Ward, dalam Ng, Wang, \& Chan, 2017). Oleh karena itu, penelitian ini ingin lebih fokus menelaah hubungan kecerdasan budaya dengan penyesuaian diri dalam konteks budaya yang berbeda.

Kecerdasan budaya adalah kemampuan individu untuk dapat beradaptasi dan mengembangkan potensi secara efektif dalam suatu konteks budaya yang baru (Earley \& Ang, 2003; Ang, Rockstuhl, \& Tan, 2015). Kecerdasan budaya juga didefinsikan sebagai kemampuan seseorang dalam memelajari pengetahuan-pengetahuan yang befokus pada konteks-konteks budaya (Thomas, 2006). Kecerdasan budaya menekankan pada kemampuan untuk berinteraksi dengan orang-orang yang berasal dari latar belakang budaya yang berbeda (Thomas, 2006). Earley dan Ang (dalam Ahmadi, Shahmohamadi, \& Araghi, 2011) menjelaskan bahwa kecerdasan budaya memiliki pengaruh dalam keberhasilan dan kinerja pekerjaan, serta memiliki hubungan dengan perilaku adaptif yang dipengaruhi oleh kepribadian, keluarga, organisasional, dan karakteristik budaya lokal.

Kecerdasan budaya terdiri dari dua dimensi yaitu dimensi pengetahuan budaya yang terinternalisasi (internalized cultural knowledge) yang merupakan faktor kognitif dan dimensi fleksibilitas budaya yang efektif (effective cultural flexibility) yang merupakan dimensi motivasional. Pengetahuan budaya yang terinternalisasi menggambarkan kesadaran individu tentang pengetahuan terkait dengan budaya yang diperoleh melalui pengalaman dan proses kognitif. Pengetahuan budaya yang terinternalisasi mewakili kecerdasan umum yang mencerminkan pengalaman dan proses belajar, seperti memori (Côté \& Miners, dalam Bucker, Furrer, \& Lin, 2015). Sementara fleksibilitas budaya yang efektif menggambarkan kemampuan seseorang dalam verbal ataupun non-verbal dengan mengukur motivasi dan perilaku. Motivasi merupakan kemampuan individu untuk mengarahkan perhatiannya untuk belajar dan menempatkan diri dalam situasi yang berbeda secara budaya dengan asumsi individu dengan motivasi yang tinggi memiliki rasa percaya diri yang tinggi atas kemampuannya dalam 
berinteraksi di lingkungan dengan budaya yang berbeda, sementara perilaku menggambarkan kemampuan individu dalam berperilaku ketika berinteraksi dengan masyarakat yang berbeda budaya, baik secara verbal ataupun non-verbal (Bucker dkk., 2015).

Berdasarkan pemaparan di atas, penelitian ini dilakukan untuk melihat hubungan antara kecerdasan budaya dengan penyesuaian diri dalam konteks budaya yang berbeda pada mahasiswa Indonesia yang kuliah di luar negeri.

\section{METODE}

\section{Partisipan}

Partisipan dalam penelitian ini adalah mahasiswa Indonesia (Warga Negara Indonesia, WNI) yang sedang melanjutkan pendidikan di luar negeri. Penelitian ini menggunakan teknik non probability sampling dalam menjaring partisipan. Untuk kemudahan proses pengambilan data, digunakan teknik incidental sampling. Partisipan penelitian ini adalah 105 mahasiswa Indonesia yang berkuliah di luar negeri dan tersebar dari negara Inggris, Amerika, Selandia Baru, Australia, Jerman, Arab Saudi, Belanda, China, Italia, Jepang, Jerman, Malaysia, Mesir, Pakistan, Perancis, Sudan, Taiwan, dan Turki.

\section{Desain}

Penelitian ini tergolong dalam penelitian kuantitatif dengan metode korelasional untuk melihat hubungan antara kedua variabel. Penelitian ini termasuk dalam tipe penelitian crosssectional karena hanya melakukan sekali pengambilan data.

\section{Prosedur}

Prosedur pengambilan data penelitian diawali dengan melakukan adaptasi terhadap kedua alat ukur, yaitu dengan melakukan terjemahan ke bahasa Indonesia, melakukan penerjemahan kembali, evaluasi dari dua orang ahli di bidang Psikologi Sosial, uji keterbacaan terhadap enam orang partisipan, dan melakukan uji coba terhadap 40 partisipan.

Penyesuaian diri dalam konteks budaya diukur dengan menggunakan alat ukur Sociocultural Adjustment Scale (SCAS) yang disusun oleh Ward dan Kennedy (1999). Alat ukur tersebut terdiri dari 20 butir dan berskala $1-5$ ( $1=$ tidak sulit; $2=$ sedikit sulit; $3=$ cukup sulit; 4 
$=$ sulit; 5 = sangat sulit). SCAS merupakan alat ukur unidimensional dan memiliki skor reliabilitas yang cukup baik, yaitu .89 (Ward \& Kennedy, 1999).

Alat ukur yang digunakan untuk mengukur kecerdasan budaya adalah Cultural Intelligence Scale (CQS) yang dikembangkan oleh Bucker dkk. (2015). CQS terdiri atas 12 butir, menggunakan skala Likert ( 1 = sangat tidak sesuai hingga 5 = sangat sesuai). CQS merupakan alat ukur multidimensional, memiliki skor reliabilitas sebesar .83 pada dimensi pengetahuan budaya yang terinternalisasi dan .71 pada dimensi fleksibilitas budaya yang efektif (Bucker dkk., 2015).

Berikut ini adalah hasil uji coba kedua alat ukur yang digunakan dalam penelitian ini:

Tabel 1.

Hasil Uji Coba Alat Ukur Penelitian

\begin{tabular}{ccccc}
\hline Variabel & Dimensi & Cronbach' $\alpha$ & $\begin{array}{c}\text { No. } \\
\text { Butir }\end{array}$ & $\begin{array}{c}\text { rentang corrected } \\
\text { item total } \\
\text { correlation }\end{array}$ \\
\hline & $\begin{array}{c}\text { Pengetahuan budaya } \\
\text { yang terinternalisasi (ICK) }\end{array}$ & .787 & $\begin{array}{c}1,2,3, \\
4,5,6,7\end{array}$ & $.411-.627$ \\
Kecerdasan budaya & $\begin{array}{c}\text { Fleksibilitas budaya yang } \\
\text { efektif (ECF) }\end{array}$ & .609 & $8,9,10$, & $.250-.461$ \\
$\begin{array}{c}\text { Penyesuaian diri } \\
\text { dalam konteks } \\
\text { budaya }\end{array}$ & $\begin{array}{c}\text { Empati dan keterkaitan } \\
\text { budaya serta upaya dan } \\
\text { risiko impersonal (SCAS) }\end{array}$ & .897 & 11,12 & \\
\hline
\end{tabular}

Berdasarkan tabel 1 diketahui bahwa kedua alat ukur penelitian memiliki nilai cronbach $\alpha>$.6. Berdasarkan nilai tersebut, maka kedua alat ukur dapat dinyatakan reliabel dan dapat digunakan dalam penelitian.

\section{ANALISIS DAN HASIL}

Penelitian ini melibatkan 105 partisipan laki-laki $(n=56)$ dan perempuan $(n=49)$, dan partisipan yang berkuliah di negara yang menggunakan bahasa Inggris $(n=21)$ dan yang tidak menggunakan bahasa Inggris $(n=84)$. Sebelum melakukan uji korelasi, peneliti melakukan uji normalitas pada kedua variabel. 
Tabel 2.

Nilai Distribusi Normal

$\begin{array}{ccc}\text { Variabel } & \text { Kolmogorov-Smirnov } & \boldsymbol{p} \\ \text { CQ_ICK } & 0.891 & .405 \\ \text { CQ_ECF } & 1.140 & .148 \\ \text { SCAS } & 0.681 & .742\end{array}$

\section{Analisis Data}

Peneliti melakukan kontrol pada variabel penggunaan bahasa Inggris. Hal tersebut dikarenakan bahasa Inggris umumnya resmi digunakan pada banyak literatur dan buku, dunia bisnis dan pendidikan, teknologi, pengobatan, serta berbagai aspek lainnya di 60 negara (Crystal, dalam Pennycook, 2017), dan bahasa Inggris mulai diajarkan secara intensif sejak kelas 4 SD (Lauder, 2008). Selain itu, dalam uji beda ditemukan perbedaan antara negara yang menggunakan bahasa Inggris sebagai bahasa utama dengan negara yang tidak menggunakan bahasa Inggris sebagai bahasa utama.

Tabel 3.

Uji Beda SCAS Berdasarkan Variabel Penggunaan Bahasa

\begin{tabular}{ccccc}
\hline Data partisipan & $\boldsymbol{N}$ & Mean & Std. Deviasi & $\begin{array}{c}\text { Signifikansi }(\boldsymbol{t}) \\
\text { (SCAS) }\end{array}$ \\
\hline Inggris & 21 & 76.38 & 8.453 & $2.153^{*}$ \\
\hline Non-Inggris & 84 & 71.15 & 14.461 &
\end{tabular}

Keterangan: ${ }^{*}=$ signifikan pada level .05

Selain itu, peneliti juga melakukan kontrol pada variabel jenis kelamin. Hal tersebut dikarenakan terdapat perbedaan signifikan antara laki-laki dan perempuan pada variabel CQ.

Tabel 4.

Uji Beda CQ Berdasarkan Variabel Jenis Kelamin

\begin{tabular}{|c|c|c|c|c|c|c|c|}
\hline \multirow{2}{*}{ Data partisipan } & \multirow{2}{*}{$N$} & \multicolumn{2}{|c|}{ Rata-rata } & \multicolumn{2}{|c|}{ Std. Deviasi } & \multicolumn{2}{|c|}{ Signifikansi $(t)$} \\
\hline & & ICK & ECF & ICK & ECF & ICK & ECF \\
\hline Laki-laki & 56 & 23.89 & 19.62 & 3.779 & 3.404 & \multirow{2}{*}{$-3.197^{*}$} & \multirow{2}{*}{$-2.088^{*}$} \\
\hline Perempuan & 49 & 26.06 & 20.88 & 3.071 & 2.627 & & \\
\hline
\end{tabular}

Keterangan: * signifikan pada level .05

\section{Hasil Uji Penelitian}

Setelah dilakukan analisis data awal, peneliti melakukan uji korelasi dengan teknik parsial dengan kontrol pada variabel jenis kelamin dan penggunaan bahasa Inggris sebagai bahasa utama. Hasil uji korelasi dapat dilihat pada tabel 5. 
Tabel 5.

Uji Korelasi CQ dan SCAS

\begin{tabular}{cccc}
\hline Kontrol & Dimensi & $\boldsymbol{r}$ & $\boldsymbol{p}$ \\
\hline \multirow{2}{*}{ Sebelum dikontrol } & Pengetahuan budaya & .227 & $.020^{*}$ \\
& Fang terinternalisasi (ICK) & .151 & .125 \\
Kontrol jenis kelamin \& & Pengetahuan budaya & .206 & $.037^{*}$ \\
bahasa & yang terinternalisasi (ICK) & .135 & .173 \\
\hline
\end{tabular}

Keterangan: * = signifikan pada level .05

Berdasarkan hasil uji analisis dengan teknik korelasi bivariat ditemukan bahwa hubungan antara dimensi pengetahuan budaya yang terinternalisasi dan penyesuaian diri dalam konteks budaya adalah $r=.227(p<.05)$ yang berarti berhubungan positif secara signifikan, namun memiliki tingkat hubungan yang rendah. Artinya, semakin tinggi pengetahuan individu mengenai budaya, maka akan semakin baik kemampuan individu dalam menyesuaikan diri dalam koteks budaya berbeda. Sementara itu, tidak terdapat hubungan antara dimensi fleksibilitas budaya yang efektif dan penyesuaian diri dalam konteks budaya $(r=.151, p>.05)$.

Setelah peneliti melakukan kontrol pada jenis kelamin dan bahasa, ditemukan hubungan antara dimensi pengetahuan budaya yang terinternalisasi dan penyesuaian diri dalam konteks budaya menjadi $r=.206$ ( $p<.05)$, yang berarti berhubungan positif secara signifikan, namun memiliki tingkat hubungan yang rendah pula. Sedangkan hubungan antara dimensi fleksibilitas budaya yang efektif dengan penyesuaian diri dalam konteks budaya tetap menunjukkan hasil yang tidak signfikan $(r=.135, p>.05)$. Adapun hasil dari perhitungan korelasi parsial yang menggambarkan bahwa variabel jenis kelamin dan bahasa tidak banyak memengaruhi hubungan antara masing-masing dimensi kecerdasan budaya dengan penyesuaian diri dalam konteks budaya yang berbeda (lihat tabel 5).

\section{DISKUSI}

Dalam variabel kecerdasan budaya, perempuan memiliki nilai lebih tinggi dibandingkan laki-laki pada dimensi pengetahuan budaya yang terinternalisasi dan pada dimensi fleksibilitas budaya yang efektif. Hal tersebut mengindikasikan bahwa perempuan memiliki kecerdasan budaya yang lebih baik daripada laki-laki. Hasil ini mendukung penelitian Bucker dkk. (2015) yang menjelaskan bahwa perempuan memiliki kecerdasan budaya yang lebih tinggi 
dibandingkan laki-laki. Oleh karenanya, dapat diasumsikan bahwa perempuan akan lebih mampu menyerap pengetahuan-pengetahuan budaya yang baru, mengembangkan kecerdasan budaya, serta memiliki kecenderungan untuk dapat lebih sukses dalam menyelesaikan tugas yang diberikan (Bucker dkk., 2015). Hasil tersebut dikarenakan perempuan mampu untuk menyeimbangkan tugas-tugas mereka di luar negeri, memiliki kemampuan untuk menyesuaikan diri dalam interaksi di konteks budaya yang berbeda, memiliki tingkat empati yang tinggi, lebih bersifat mengasuh, lebih kooperatif, dan memiliki kemampuan sosial yang lebih baik (Linehan; Harvey; Martin, dkk; Nicholson, dalam Haslberger, 2010)

Hasil analisis lain yang dilakukan adalah uji beda pada negara-negara yang menggunakan bahasa Inggris sebagai bahasa utama dan yang tidak menggunakan bahasa Inggris sebagai bahasa utama. Uji beda berdasarkan penggunaan bahasa ini dilakukan karena faktor bahasa sering dianggap sebagai permasalahan inti dalam melakukan penyesuaian diri (Ward \& Kennedy, 1999). Hasil survei awal yang dilakukan oleh peneliti juga menunjukkan bahwa permasalahan yang paling besar dihadapi oleh mahasiswa yang berkuliah di luar negeri adalah bahasa. Selain itu, hal ini juga dikarenakan bahasa Inggris adalah bahasa yang umumnya resmi digunakan pada banyak literatur dan buku, dunia bisnis dan pendidikan, teknologi, pengobatan, serta berbagai aspek lainnya di 60 negara (Crystal, dalam Pennycook, 2017), dan karena bahasa Inggris sudah mulai diajarkan secara intensif sejak kelas 4 SD (Lauder, 2008).

Dari hasil perhitungan statistik ditemukan bahwa partisipan yang berkuliah di negara yang menggunakan bahasa Inggris sebagai bahasa utama memiliki kemampuan penyesuaian diri dalam konteks budaya yang lebih baik dibandingkan dengan partisipan yang berkuliah di negara yang tidak menggunakan bahasa Inggris sebagai bahasa utama $(p<.05)$. Peneliti berasumsi bahwa partisipan yang sudah memiliki pemahaman tentang bahasa Inggris yang baik akan lebih mudah dalam mengimplementasikannya dalam komunikasi sehari-hari. Hal tersebut dikarenakan bahasa Inggris adalah bahasa yang paling banyak digunakan sebagai bahan rujukan dalam dunia pendidikan, teknologi, pengobatan, dan banyak aspek lainnya (Crystal, dalam Pennycook, 2017) dan juga karena bahasa Inggris sudah diajarkan secara resmi di Indonesia saat siswa menginjak kelas 4 SD (Lauder, 2008), sehingga mahasiswa Indonesia telah terbiasa dengan bahasa Inggris. Oleh karena itu, maka memungkinkan mahasiswa Indonesia untuk dapat lebih mudah menyesuaikan diri. Hal tersebut sesuai dengan teori Ward dan Kennedy (1999) yang menjelaskan keberagaman di negara asal dapat memengaruhi kemampuan individu dalam 
menyesuaikan diri di budaya yang berbeda, yang dalam hal ini bahasa Inggris menjadi salah satu keberagaman tersebut.

Dalam uji korelasi, terdapat hubungan antara kecerdasan budaya pada dimensi pengetahuan budaya yang terinternalisasi dengan penyesuaian diri dalam konteks budaya yang berbeda $(p<.05)$, dan tidak terdapat hubungan antara dimensi fleksibilitas budaya yang efektif dengan penyesuaian diri dalam konteks budaya yang berbeda $(p>.05)$. Hasil yang sama juga ditemukan ketika sudah dilakukan kontrol statistik terhadap variabel jenis kelamin dan penggunaan bahasa Inggris. Dari hasil uji korelasi parsial, diketahui bahwa perbedaan skor sebelum dan sesudah dikontrol tidak terlalu jauh. Artinya, jenis kelamin dan bahasa tidak menyebabkan perubahan signifikan pada hubungan antara kedua dimensi kecerdasan budaya dengan dimensi penyesuaian diri dalam konteks budaya yang berbeda.

Berdasarkan uji korelasi yang dilakukan sebelum dan sesudah kontrol ditemukan bahwa dimensi pengetahuan budaya yang terinternalisasi berkorelasi positif secara signifikan dengan dimensi penyesuaian diri dalam konteks budaya yang berbeda. Hubungan antara dimensi pengetahuan budaya yang terinternalisasi dengan dimensi penyesuaian diri dalam konteks budaya yang berbeda diperkirakan juga disebabkan oleh adanya kesamaan dimensi pada kedua variabel tersebut. Penyesuaian diri dalam konteks budaya yang berbeda juga memiliki dimensi kognitif dan komunikasi yang mengukur pemahaman individu terhadap nilai dan pandangan masyarakat lokal (Ward \& Kennedy, 1999). Hasil ini sesuai dengan Ward dan Kennedy (1999) yang menjelaskan bahwa pengetahuan individu tentang suatu budaya atau tempat yang akan ditempati membantu proses penyesuaian diri di lingkungan tersebut. Hal tersebut dikarenakan aspek kognitif memiliki unsur pengetahuan dan kemampuan berpikir yang digunakan untuk memecahkan suatu permasalahan (Bandura, 1989) yang dalam hal ini adalah masalah penyesuaian diri, sehingga individu akan lebih mudah dalam menerapkan suatu perilaku tertentu.

Hasil uji korelasi juga menunjukkan adanya hubungan yang tidak signifikan antara dimensi fleksibilitas budaya yang efektif dengan dimensi penyesuaian diri dalam konteks budaya yang berbeda. Hasil yang tidak signifikan tersebut diasumsikan terjadi karena dimensi fleksibilitas budaya yang efektif menggambarkan motivasi yang dalam hal ini menilai rasa kepercayaan diri pada kemampuan individu terhadap apa yang telah dilakukan di dalam budaya yang berbeda, sedangkan penyesuaian diri dalam konteks budaya yang berbeda merupakan variabel yang mengukur pengalaman yang benar-benar dialami individu secara nyata. Pada 
penelitian lain, persepsi seseorang terhadap dirinya yang memiliki sebuah kemampuan tertentu tidak memiliki keterkaitan dengan kompetensi dalam berinteraksi dengan individu lain yang berasal dari budaya yang berbeda (Cole \& McNulty, 2011).

Pada penelitian ini, peneliti mencoba untuk memasukkan faktor-faktor yang secara teoretis dapat memiliki hubungan dengan kecerdasan budaya dan penyesuaian diri dalam konteks budaya. Akan tetapi masih terdapat beberapa keterbatasan dalam kontrol faktor-faktor tersebut, sehingga diasumsikan memengaruhi hasil penelitian. Adapun faktor-faktor yang dimaksud adalah faktor lama tinggal yang hanya dibuat secara dikotomi, sehingga tidak terlalu membedakan partisipan yang sudah tinggal di luar negeri dalam jangka waktu yang lama. Selain itu, penelitian ini tidak memiliki data mengenai pengalaman partisipan tinggal atau menempuh pendidikan di negara lain sebelum mengikuti penelitian ini. Peneliti juga tidak melakukan kontrol terhadap negara tempat partisipan berkuliah, sehingga memungkinkan munculnya eror karena tidak mengukur perbedaan budaya dalam aspek lainnya, seperti jarak perbedaan budaya, norma sosial yang berlaku, serta kebiasaan berlaku di negara berkuliah.

\section{SIMPULAN DAN SARAN}

\section{Simpulan}

Hasil dari penelitian ini menunjukkan bahwa terdapat hubungan antara dimensi pengetahuan budaya yang terinternalisasi dengan penyesuaian diri dalam konteks budaya yang berbeda, yang berarti aspek kognitif tentang budaya dapat mepengaruhi proses penyesuaian yang dihadapi oleh mahasiswa Indonesia di luar negeri. Hasil lain yang ditemukan adalah perempuan memiliki kemampuan penyesuaian diri dalam konteks budaya yang lebih baik dibandingkan laki-laki dan penyesuaian budaya di negara yang menggunakan bahasa Inggris sebagai bahasa utama lebih mudah dibandingkan dengan negara yang tidak menggunakan bahasa Inggris sebagai ibu bahasanya.

\section{Saran Teoretis}

Beberapa saran penelitian teoretis yang dapat diberikan untuk perbaikan penelitian berikutnya. Pertama, perlu dilakukan penelitian lebih lanjut dengan menentukan satu negara dengan karakteristik tertentu, seperti pemahaman nilai-nilai dalam kebudayaan atau aspek kebudayaan lainnya, sehingga hasil dapat lebih berfokus pada satu aspek yang spesifik dan dapat 
digeneralisasikan pada mahasiswa yang akan berkuliah di negara tersebut. Kedua, pengukuran lama tinggal di luar negeri dapat dilakukan dengan meminta partisipan melengkapi data lama tinggal dengan mencantumkan satuan tahun dan bulan, sehingga analisis dapat dilakukan lebih mendalam. Ketiga, penelitian selanjutnya sebaiknya melakukan kontrol terhadap variabel pengalaman tinggal di luar negeri atau menjalani pendidikan di negara lain, agar dapat memperoleh hasil yang lebih akurat dalam perhitungan.

\section{Saran Praktis}

Sementara itu, saran praktis berdasarkan hasil penelitian ini adalah bagi calon mahasiswa yang hendak berkuliah ke luar negeri perlu melakukan persiapan terutama memelajari negara tujuannya seperti budaya, cuaca, birokrasi, dan lain sebagainya dengan lebih baik agar dapat lebih mudah menyesuaikan diri. Kemudian, bagi lembaga penyedia beasiswa, komunitas pelajar Indonesia di luar negeri untuk bisa lebih memberikan pengarahan kepada mahasiswa Indonesia yang kuliah di negeri terkait dengan informasi di negara berkuliah, sehingga melancarkan aktivitas mahasiswa tersebut.

\section{REFERENSI}

Ahmadi, Y., Shahmohamadi, A., \& Araghi, M. M. (2011). The study of effect of socio-cultural factor on cultural intelligence (CI) (case study: Sanandaj City). International Journal of Humanities and Social Science, 4(12), 161-168.

Ang, S., Rockstuhl, T., \& Tan, M. L., (2015). Cultural intelligence and competencies. Dalam J. Wright (Ed.), International Encyclopedia of Social \& Behavioral Sciences $\left(2^{\text {nd }}\right.$ ed., hlm. 433-439). Oxford, UK: Elsevier.

Bandura, A. (1989). Social cognitive theory. Dalam R. Vasta (Ed.), Annals of child development, Vol. 6: Six theories of child development (hlm. 1-60). Greenwich, CT: JAI Press.

Bemak, F. \& Chung, R. C. Y. (1998). Vietnamese amerasians: Predictors of distress and selfdestructive behavior. Journal of Counseling \& Development, 76, 452-458.

Black, J. S. (1988). Work role transitions: A study of American expatriate managers in Japan. Journal of International Business Studies, 19(2), 277- 294. 
Bohrer, I. E. (2011). Study abroad increases profesional prospects. Ditemu kembali dari http://www.transitionsabroad.com/listings/study/articles/study-abroad-increasesprofessional-job-prospects.shtml

Bucker, J., Furrer, O., \& Lin, Y. (2015). Measuring cultural intelligence (CQ): A new test of the CQ scale. International Journal of Cross Cultural Management, 15(3), 259-284.

Cole, N., \& McNulty, Y. (2011). Why do female expatriates "fit-in" better than males? An analysis of self-transcendence and socio-cultural adjustment. Cross Cultural Management: An International Journal, 18(2), 144-164.

Dwyer, M. M., \& Peters C. K. (2004). The benefits of study abroad. Transitions Abroad, 27(5), $56-57$.

Earley, P. C., \& Ang. S. (2003). Cultural intelligence: Individual interactions across cultures. Santa Clara County, CA: Stanford University Press.

Guðmundsdóttir, S. (2013). The relationship between socio cultural adjustment and extrinsic job satisfaction. International Journal of Business and Social Science, 4(10), 43-48.

Haslberger, A. (2010). Gender differences in expatriate adjustment. European Journal of International Management, 4(1-2), 163-183.

Koveshnikov, A., Wechtler, H., \& Dejoux, C. (2013). Cross-cultural adjustment of expatriates:

The role of emotional intelligence and gender. Journal of World Business, 49(3), 362-371.

Lauder, A. (2008). The status and function of English in Indonesia: A review of key factors. Sosial Humaniora, 12(1), 9-20.

Markova, V. (2006). Sociocultural and psychological features of adaptation among Asian foreign students in Archangelsk, Russia and Umea, Sweden. Ditemu kembali dari http://www.phmed.umu.se/digitalAssets/30/30037_2006-4-veronika-markova.pdf

Mayer, J. D., Roberts, R. D., \& Barsade, S. G. (2008). Human abilities: Emotional intelligence. The Annual Review of Psychology, 59, 507-536.

Mazzarol, T., \& Soutar, G. N. (2002). Push-pull factors influencing international student destination choice. International Journal of Educational Management, 16(2), 82-90.

Ng, T. K., Wang, K. W. C., \& Chan, W. (2017). Acculturation and cross-cultural adaptation: The moderating role of social support. International Journal of Intercultural Relations, 59, 19-30.

Oatey, H. S., \& Xiong, Z. (2006). Chinese students' psychological and sociocultural adjustment to Britain: an empirical study. Language, Culture and Curriculum, 19(1), 37-53. 
Pennycook, A. (2017). The cultural politics of English as an international languange. New York, NY: Routledge Taylor and Francis Group.

Searle, W., \& Ward, C. (1990). The prediction of psychological and sociocultural adjustment druing cross-cultural transtitions. International Journal of Interultural Relations, 14(4), 449-464.

Smith, R. A., \& Khawaja, N. G. (2011). A review of the acculturation experiences of international students. International Journal of Intercultural Relations, 35(6), 699-713.

Thomas, D. C. (2006) Domain and development of cultural intelligence: The importance of mindfulness. Group and Organization Management, 31(1), 78-99.

Universitas Negeri Malang. (2017). Academic and social orientation training pack predeparture English course. Malang: Department of English, Faculty of Letters, Universitas Negeri Malang.

Wang, C. C. D., \& Mallinckrodt, B. (2006). Acculturation, attachment, and psychosocial adjustment of Chinese/Taiwanese international students. Journal of Counseling Psychology, 53, 422-433.

Ward, C., \& Kennedy, A. (1994). Acculturation strategies, psychological adjustment, and sociocultural competence during cross-cultural transitions. Int. J. Intercultural Rel, 18(3), 329-343.

Ward, C., \& Kennedy, A. (1999). The measurement of sociocultural adaptation. International Journal of Intercultural Relations, 23(4), 659-677.

Wilson, G. P. (2011). Fitting in: Sociocultural adaptation of international graduate students. Ditemu kembali dari https://opencommons.uconn.edu/cgi/ viewcontent.cgi?referer=https://www.google.co.id/\&httpsredir=1\&article=1020\&context =nera $\_2011$

Zhao, L. (2010). Socio-cultural adjustment of international students as expatriates in America. Ditemu kembali dari https://digitalcommons.wku.edu/cgi/ viewcontent.cgi?referer=https://www.google.co.id/\&httpsredir=1\&article=1230\&context $=$ theses 